\section{Auch nach Ende der Kolik kann ein Stein im Ureter stecken}

Sind Patienten nach einer Nierenkolik wieder schmerzfrei, ist das nicht gleichbedeutend mit dem Abgang des Konkrements. Bei jedem vierten sind danach noch Steine im Ureter zu finden.

\begin{abstract}
A $\mathrm{n}$ einer Studie am Massachusetts General Hospital in Boston waren 52 Patienten beteiligt. Sie alle hatten eine durch Konkremente bedingte akute renale Kolik erlitten. Der mittlere Durchmesser der Steine betrug zwischen $4,2 \mathrm{~mm}$ axial und 4,9 $\mathrm{mm}$ koronal. Bei der Nachuntersuchung gut einen Monat nach dem Ereignis gaben alle Patienten an, seit mindestens drei Tagen schmerzfrei zu sein. 14 der 52 (27\%) wiesen allerdings nach wie vor Konkremente im Ureter auf.

Keiner der verbliebenen Steine hatte seine Lage gegenüber dem Ausgangspunkt wesentlich verändert. In der multivariaten Analyse war nicht zu erkennen, dass die Größe oder die Lokalisation der Steine mit der Wahrscheinlichkeit eines Abgangs assoziiert wäre. Eine
\end{abstract}

Mikrohämaturie fand sich nur bei $16 \%$ der Patienten mit Konkrementen, aber bei $50 \%$ derjenigen, deren Steine tatsächlich abgegangen waren. Der Nachweis einer Mikroblutung wäre demzufolge ungeeignet, die Persistenz von Konkrementen zu belegen. Um den Wert einer vorhandenen oder fehlenden mikroskopischen Hämaturie mit Blick auf die Steinpassage einzuschätzen, sei die Teilnehmerzahl der Untersuchung aber wahrscheinlich $\mathrm{zu}$ gering, schreiben Hernandez et al. Die mittlere Steingröße der beteiligten Patienten bewegte sich immerhin in einem Bereich, bei dem bei etwa der Hälfte der Fälle eine Intervention nötig wird, weil die Konkremente nicht spontan abgehen. Bleibt so ein Stein an Ort und Stelle, ohne Schmerzen $\mathrm{zu}$ verursachen, ist eine stumme $\mathrm{Ob}$ - struktion die Folge, die bis zur Hydronephrose führen kann.

Warum es überhaupt möglich ist, dass Uretersteine schmerzlos persistieren, ist unklar. Hernandez et al. halten zwei Mechanismen für möglich: Zum einen könnte die kontralaterale Niere die Filtrationsrate erhöhen, was auf der betroffenen Seite einen niedrigeren Urinfluss und damit ein Abflauen der Schmerzen bewirken könnte. Zum anderen könnten die Konkremente ihre Position leicht verändert haben, den Harnleiter somit in geringerem Maß verlegen und weniger Schmerzen verursachen.

Fazit: Die Bostoner Urologen empfehlen, alle Steinpatienten ohne nachweisliche Konkrementpassage - der Patient bringt den Stein zur Analyse oder hat ihn wenigstens abgehen sehen - bei der Nachuntersuchung zum Schutz der Nierenfunktion noch einmal einer bildgebenden Diagnostik zu unterziehen.

Dr. Robert Bublak

Hernandez $\mathrm{N}$ et al. Cessation of ureteral colic does not necessarily mean that a ureteral stone has been expelled. J Urol. 2017; doi: https://doi. org/10.1016/j.juro.2017.

\title{
Kinder älterer Väter erkranken seltener an Hodenkrebs
}

Söhne von Männern, die in fortgeschrittenem Alter Vater geworden sind, haben ein geringeres Risiko für testikuläre Keimzelltumoren. Vor allem Seminome treten bei ihnen weniger häufig auf als bei Söhnen junger Väter.

\begin{abstract}
aut Ergebnissen einer israelischen LStudie bedeuten ältere Väter offenbar für ihre Söhne einen gewissen Schutz vor Hodentumoren, wie Hagai Levine von der Hebräischen Universität Hadassah in Jerusalem und Kollegen berichten.
\end{abstract}

Das Risiko für testikuläre Keimzelltumoren sinkt mit jedem zusätzlichen Lebensjahr des Vaters um 1,7 \%. Die Söhne von jungen Vätern im Alter zwischen 15 und 24 Jahren erkranken um $41 \%$ häufiger an Seminomen als Söhne, deren Väter bei der Geburt bereits mindestens 30 Jahre alt waren. Die Assoziation erwies sich als unabhängig vom Jahr der
Geburt, von der Dauer der Ausbildung, der Körpergröße, der Abstammung, einem Kryptorchismus in der Anamnese, von der Zahl der Geschwister und der Position in der Geschwisterfolge. Das Alter der Mutter hatte nach Berücksichtigung des Vateralters ebenfalls keinen Einfluss auf das Risiko für Geschwülste testikulärer Keimzellen, welchen histologischen Typs auch immer.

Levine und sein Team hatten für ihre Kohortenstudie Angaben zu mehr als einer Million Männer zur Verfügung. Sie waren im Alter zwischen 16 und 19 Jahren im Zuge der Musterung medizinisch untersucht und danach im Mittel 15,6
Jahre lang nachbeobachtet worden. Ihre Daten wurden mit den Einträgen im israelischen nationalen Krebsregister abgeglichen.

Fazit: Die Forscher verweisen auf Indizien, wonach Keimzelltumoren und andere Manifestationen testikulärer Dysgenesie bereits früh im Leben angelegt werden. Möglicherweise erkläre sich das höhere Seminomrisiko für Söhne junger Väter mit altersabhängigen Unterschieden in der Keimzellselektion, so Levine und Mitarbeiter - etwa aufgrund der Telomerlängen oder epigenetischer Veränderungen. „Das könnte dazu führen, dass bei älteren, nicht aber bei jüngeren Männern die Wahrscheinlichkeit sinkt, Feten zu zeugen, die Seminome entwickeln werden."

Dr. Robert Bublak

Levine $\mathrm{H}$ et al. Paternal age and risk of testicular germ cell tumors: a cohort study of 1,000,000 men. Andrology. 2017; doi: https://doi. org/10.1111/andr.12422. 